\title{
DISRUPTIVE INNOVATION DALAM KAJIAN HUKUM PERSAINGAN USAHA
}

\author{
Oleh : Ibnu Rusydi, S.H., M.Pd.I. *)
}

\begin{abstract}
Disruptive innovation can be interpreted as a novel that creates new markets, disrupts or destroys existing markets, which can ultimately replace previous technologies. The birth of disruptive innovation provides ease of accessibility and relatively more affordable cost for the user community. On this side, disruptive innovation is a market development that has a good impact on society and an increase in economic value on the consumer and business side. On the other hand, disruptive innovation is one of the threats to a similar industry that has previously been developed. This paper seeks to reveal the phenomenon of disruptive innovation in the study of business competition law.
\end{abstract}

Keywords: Innovation, Disruptive Innovation, Business Competition Law.

\section{ABSTRAK}

Disruptive innovation dapat diartikan sebagai suatu inovasi yang menciptakan pasar baru, mengganggu atau merusak pasar yang sudah ada, yang pada akhirnya dapat menggantikan teknologi terdahulu. Lahirnya disruptive innovation memberikan kemudahan aksesbilitas serta biaya yang relatif lebih terjangkau bagi masyarakat pengguna. Pada sisi ini, disruptive innovation merupakan perkembangan pasar yang berdampak baik terhadap masyarakat dan peningkatan nilai ekonomi pada sisi konsumen dan pelaku usaha. Pada sisi lainnya, disruptive innovation merupakan salah satu ancaman bagi industri sejenis yang sebelumnya telah berkembang. Tulisan ini berusaha mengungkap fenomena disruptive innovation dalam kajian hukum persaingan usaha.

Kata kunci: Inovasi, Disruptive Innovation, Hukum Persaingan Usaha.

\section{PENDAHULUAN}

Inovasi merupakan suatu ciri pembentuk bisnis masa kini yang menandakan era eksponensial dimana perubahan tidak lagi bisa dihitung dengan pola pertambahan maupun perkalian namun sudah mengikuti pola pemangkatan (powering) mengikuti konsep matematika dalam pemangkatan suatu bilangan. Kalau pada waktu lalu jargon bisnis yang mengemuka adalah diffentiate or die, sekarang menjadi innovatie or die. Hal ini menunjukkan betapa pentingnya inovasi dalam dunia bisnis.

\footnotetext{
*) Tenaga Pengajar Fakultas Hukum Universitas Galuh
} 
Inovasi dalam praktik bisnis menjadi kunci penting untuk membawa sukses bisnis itu sendiri. Begitu pentingnya inovasi, tidak mengherankan apabila dalam menjalankan kegiatan bisnisnya membawa semangat inovasi itu sendiri dalam slogan-slogannya. Seperti dalam konteks perusahaan Suzuki dengan slogannya yang dikenal "Suzuki, inovasi tiada henti", begitu juga dengan perusahaan Yamaha dengan slogan "Yamaha selalu di depan" dan banyak lagi contoh-contoh slogan lain yang ber-spirit-kan inovasi.

Inovasi teknologi pada era teknologi informasi sebagaimana saat ini ternyata tidak hanya berhenti pada soal menghasilkan produk baru atau servis baru. Namun pada era ini, inovasi teknologi telah menimbulkan dampak negatif terhadap perkembangan bisnis konvensional, dimana kehadiran inovasi teknologi telah menyebabkan bisnis konvensional terganggu atau gulung tikar. Kondisi semacam ini disebut dengan Disruptive Innovation atau diartikan sebagai inovasi yang mengganggu.

Dewasa ini, sering warga Indonesia mendengar mengenai munculnya pelaku dalam dunia bisnis yang mengganggu keberadaan pelaku lama. Pada dasarnya, pesaing baru tersebut memiliki keunggulan yang unik jika dibandingkan dengan pelaku incumbent. Banyak contoh yang ada, misalkan yang sampai sekarang ini masih menjadi pro-kontra, yaitu fenomena ojek online yang menggantikan ojek konvensional. Contoh lain misalnya teknologi booking hotel secara online yang menggantikan booking secara konvensional.

Edi Suandi Hamid (2017: 3) menegaskan bahwa berbagai fenomena yang ada tersebut sudah jelas terjadi bukan tanpa sebab. Pertama, perkembangan teknologi memiliki pengaruh yang sangat besar terhadap arah perubahan dan inovasi. Kedua, kebutuhan yang tinggi akan efisiensi dan efektifitas menyebabkan produsen perlu melakukan inovasi yang mewadahi. Kebutuhan akan efisiensi merupakan sebab yang kuat bagaimana produsen melakukan inovasi untuk masuk ke pasar.

Berbagai inovasi yang dibawa newcumbent sering menyebabkan perselisihan dengan incumbent. Penggunaan teknologi memberikan pelayanan yang maksimal dengan biaya yang efisien. Faktor tersebut tentu menyebabkan semakin beralihnya konsumen incumbent ke produsen newcumbent yang membawa inovasi tersebut. Tidak jarang, pengusaha incumbent yang merasa 
terganggu melakukan protes dan demo agar newcumbent dilarang beroperasi. Bahkan, tidak jarang pula terjadi bentrokan dalam aksi protes tersebut.

Windiyati Retno Sumardiyani (http://www.pikiran-rakyat.com/jawabarat/2017/07/20/) memberitakan bahwa ratusan ojek pangkalan melakukan aksi demontrasi di Gedung DPRD Kota Tasikmalaya, Kamis, 20 Juli 2017. Mereka meminta DPRD Kota Tasikmalaya menyampaikan aspirasi mereka untuk melarang ojek berbasis aplikasi atau ojek online untuk tidak beroperasi di Tasikmalaya. Perwakilan ojek pangkalan Tasikmalaya, Agus Darsono dalam orasinya mengatakan, seluruh ojek konvensional sepakat menolak keberadaan ojek online. Soalnya sejak ada ojek online masuk Tasikmalaya, pendapatan mereka berkurang drastis. Selain itu, selama ini ojek konvensional tidak pernah diajak bermusyawarah atau diajak untuk turut menjadi bagian ojek daring tersebut.

Ahmad Bil Wahid (Detiknews, Juli 2017) memberitakan bahwa pengemudi angkutan kota (angkot) se-Kota Tanggerang berdemo menolak keberadaan angkutan online di wilayah mereka. Para pendemo juga mencegat dan mengambil helm driver ojek online yang melintas. Peristiwa itu terjadi di Jalan Satria Sudirman, Tanggerang, pada Rabu 8 Maret 2017 sekitar pukul 10.20 WIB.

Keadaan cukup jelas menunjukkan adanya konflik kepentingan antara pengusaha incumbent dengan pelaku newcumbent dengan inovasi teknologi yang memudahkan. Sementara itu menurut E-Marketer (2017) jumlah pemakai Internet di Indonesia yang sudah mencapai urutan keenam terbesar di dunia, sungguh menjadi daya tarik tersendiri bagi semua pelaku usaha yang telah "godigital' tersebut. Perkiraannya, pada tahun 2018 nanti, pengguna Internet di Tanah Air akan mencapai angkat 123 juta.

Table Top 10 Countries Ranked by Internet Users 2013-2018 (in million)

\begin{tabular}{l|l|l|l|l|l|l|l}
\hline No & Country & $\mathbf{2 0 1 3}$ & $\mathbf{2 0 1 4}$ & $\mathbf{2 0 1 5}$ & $\mathbf{2 0 1 6}$ & $\mathbf{2 0 1 7}$ & $\mathbf{2 0 1 8}$ \\
\hline 1 & China* & 620.7 & 643.6 & 669.8 & 700.1 & 736.2 & 777.0 \\
\hline 2 & USA & 246.0 & 252.0 & 259.3 & 264.9 & 269.7 & 274.1 \\
\hline 3 & India & 167.2 & 215.6 & 252.3 & 283.8 & 313.8 & 346.3 \\
\hline 4 & Brazil & 99.2 & 107.7 & 113.7 & 119.8 & 123.3 & 125.9 \\
\hline 5 & Japan & 100.0 & 102.1 & 103.6 & 104.5 & 105.0 & 105.4 \\
\hline 6 & Indonesia & 72.8 & 83.7 & 93.4 & 102.8 & 112.6 & 123.0 \\
\hline 7 & Russia & 77.5 & 82.9 & 87.3 & 91.4 & 94.3 & 96.6 \\
\hline 8 & Germany & 59.5 & 61.6 & 62.2 & 62.5 & 62.7 & 62.7 \\
\hline 9 & Mexico & 53.1 & 59.4 & 65.1 & 70.7 & 75.7 & 80.4 \\
\hline 10 & Nigeria & 51.8 & 57.7 & 63.2 & 69.1 & 76.2 & 84.3 \\
\hline *) Excludes Hongkong
\end{tabular}


Benar, bahwa "disruptive innovation" ini merupakan fenomena global yang tidak mungkin dibendung begitu saja. Sekalipun demikian, sebagai sebuah negara berdaulat, tetap ada ruang bagi pengambil kebijakan publik untuk menyiasati serbuan ini agar kepentingan publik jangka panjang tetap diberikan prioritas.Kepentingan publik berjangka panjang ini setidaknya dapat dilihat dari dua sisi, namun berimplikasi secara multidimensional.

Pertama, sisi persaingan usaha. Sisi ini membahas hubungan B2B (business to business). Dari sisi ini, dunia usaha harus mengedepankan tercipta dan terpeliharanya iklim persaingan usaha yang sehat. Tidak boleh ada hambatan bagi pemain baru untuk masuk (no entry-barrier) di dalam dunia usaha Indonesia, yang pada gilirannya berakibat pada terkonsentrasinya penguasaan pasar oleh satu atau sekelompok pelaku usaha. Pasar tidak menjadi buyer's market, tetapi seller's market. Munculnya disruptive innovation tidak boleh dihadapi dengan sikap negatif, yaitu secara defensif melarangnya begitu saja, melainkan harus secara bijaksana justru perlu mengakomodasikannya agar pelaku usaha konvensional (incumbent business actors) dapat ikut memanfaatkan perkembangan ini seoptimal mungkin. Bagi pelaku usaha yang belum siap, maka tugas pemerintah untuk menyiapkan mereka. Dalam rangka itulah diperlukan strategi negara dalam menghadapi disruptive innovation ini.

Kedua, sisi perlindungan konsumen. Sisi ini lebih menyoroti hubungan B2C (business to consumer). Disruptive innovation berangkat dari perspektif kebutuhan konkret konsumen. Jadi, dari kacamata konsumen, inovasi ini tidak dianggap "mengganggu". Konsumen justru merasa terbantu karena layanan menjadi lebih efisien dan efektif. Dukungan konsumen atas keberadaan usaha yang inovasi seperti itu tidak boleh membuat konsumen justru lengah, sehingga akhirnya terjadi akumulasi kerugian pada konsumen akibat praktik curang dalam dunia usaha, dengan memanfaatkan teknologi informasi dan komunikasi sebagai medianya. Oleh sebab itu, perlindungan konsumen harus menjadi titik perhatian. Tugas negara untuk melakukan edukasi konsumen secara terusmenerus karena inovasi di bidang ini tidak pernah mengenal kata berhenti. Kedua sisi utama ini kemudian punya implikasi yang luar biasa khususnya sektor perlindungan kekayaan intelektual dan masalah-masalah sosial. 
Berdasarkan hal di atas, bagaimanakah disruptive innovation dalam kajian hukum persaingan usaha?

\section{PEMBAHASAN}

\subsection{Memahami Makna Inovasi}

Inovasi merupakan kunci bagi kesuksesan bisnis. Bahkan tidak tanggung-tanggung ada beberapa ahli berpendapat bahwa inovasi sebagai kunci dari suksesnya suatu bisnis, sehingga inovasi dipersepsikan sebagai raja atau innovation is king. (Carl Shapiro, $2005: 2$ )

Christoper M. Kalanje menyebutkan, secara umum inovasi adalah mengembangkan ide baru dan menerapkannya dalam suatu kegiatan praktis. Kata Inovasi berasal dari bahasa latin, yakni innovare yang berarti membuat sesuatu yang baru (Trina Fizzanty dkk, 2014: 37). Inovasi dapat diartikan sebagai "proses" dan atau "hasil" pengembangan dan pemanfaatan atau mobilisasi pengetahuan, keterampilan (termasuk keterampilan teknologi) dan pengalaman untuk menciptakan atau memperbaiki produk (barang dan/atau jasa), proses, dan sistem yang baru, yang memberikan nilai yang berarti atau secara signifikan (terutama ekonomi dan sosial). Inovasi sebagai suatu "objek" juga memiliki arti sebagai suatu produk atau praktik baru yang tersedia bagi aplikasi, umumnya dalam suatu konteks komersial. Sementara itu, inovasi sebagai suatu "aktivitas" merupakan proses penciptaan inovasi, seringkali diidentifkasi dengan komersialisasi suatu invensi.

Definisi inovasi menurut Kamus Besar Bahasa Indonesia (KBBI) adalah pemasukan atau pengenalan hal-hal yang baru; pembaharuan atau penemuan baru yang berbeda dari yang sudah ada atau yang sudah dikenal sebelumnya (gagasan, metode, atau alat) kemudian kata kerja ialah menginovasi yang didefinisikan sebagai menampilkan sesuatu yang baru; memperbaharui. (Suharso dan Ana Retnoningsih, 2009 : 184).

Menurut Kamus IImiah Populer yang ditulis oleh Pius A Partanto dan M. Dahlan Al Barry (2001: 266) bahwa inovasi adalah pembaharuan (bidang pengembangan kemasyarakatan, sains/iptek), adapun kata sifatnya ialah inovatif yang berarti mengarah kepada (perbaikan dan pengembangan); bersifat pembaharuan, dan orang yang melakukan inovasi disebut inovator yang dapat 
diartikan sebagai pembaharu; orang yang mendatangkan hal-hal/ide-ide metode pembaharuan; perintis ide-ide/gagasan (baru).

Inovasi dalam Bahasa Inggris, dapat diterjemahkan sebagai "The action or process of innovating or new method, idea, product, etc" yang dapat diartikan sebagai aksi atau proses pembaharuan atau metode, idea, produk baru dan lain lain (https://en.oxfordictionaries.com/definition/ innovation).

Berdasarkan beberapa definisi di atas dapat disimpulkan bahwa inovasi adalah proses menterjemahkan ide atau invensi ke dalam suatu barang atau jasa yang meciptakan nilai atau sesuatu yang konsumen akan bayar. Untuk disebut sebagai sebuah inovasi, sebuah ide harus ditiru dengan biaya ekonomis dan harus memenuhi kebutuhan spesifik. Inovasi melibatkan penerapan informasi, imajinasi, dan inisiatif yang disengaja dalam menghasilkan nilai yang lebih besar atau berbeda dari sumber daya, dan mencakup semua proses dimana gagasan baru dihasilkan dan diubah menjadi produk yang bermanfaat.

Inovasi dalam bisnis, sering terjadi ketika ide diterapkan oleh perusahaan untuk lebih memenuhi kebutuhan dan harapan pelanggan. Konsep inovasi menurut Schumpeter yang mencetuskan Theory of Economic Development pada Tahun 1912 diartikan sebagai usaha mengkreasikan dan mengimplementasikan sesuatu menjadi satu kombinasi, sehingga dengan inovasi seseorang dapat menambahkan nilai dari produk, pelayanan, proses kerja, dan kebijakan tidak hanya bagi lembaga pendidikan tetapi juga stakeholders dan masyarakat. Schumpeter mendeskripsikan perkembangan sebagai proses historis dalam perubahan struktur yang secara substansial dikendalikan oleh Inovasi (Schumpter, 2015: 90).

Schumpeter (2015 : 90) membagi inovasi menjadi 5 (lima) tipe besar : 1) peluncuran produk baru atau spesies baru dari produk yang sudah dikenal; 2) penerapan metode produksi atau penjualan produk baru (yang belum terbukti di industri); 3) pembukaan pasar baru (pasar yang cabang industrinya belum ada perwakilannya); 4) Mendapatkan sumber baru pasokan bahan baku atau barang setengah jadi; 5) Struktur industri baru seperti penciptaan atau penghancuran posisi monopoli.

Sementara, Wina Sanjaya (2008: 293) dalam bukunya Kurikulum dan Pembelajaran, inovasi diartikan sebagai sesuatu yang baru dalam situasi sosial 
tertentu dan digunakan untuk menjawab atau memecahkan suatu permasalahan.

Inovasi dalam konteks sosial membantu menciptakan metode baru untuk penciptaan aliansi, usaha bersama, jam kerja yang fleksibel, dan penciptaan daya beli pembeli. Inovasi dapat dikatakan juga suatu perubahan yang baru menuju kearah perbaikan, yang lain atau berbeda dari yang sudah ada sebelumnya, yang dilakukan dengan sengaja dan berencana atau tidak secara kebetulan.

Adapun jenis Inovasi menurut Schrumpeter (2015: 91) terdiri dari 4 jenis, yaitu :

a. Penemuan (Invention) merupakan kreasi suatu produk, jasa, atau proses baru yang belum pernah dilakukan sebelumnya. Konsep ini cenderung disebut revolusioner.

b. Pengembangan (Extension) merupakan pengembangan suatu produk, jasa, atau proses yang sudah ada. Konsep seperti ini menjadi aplikasi ide yang telah ada berbeda.

c. Duplikasi (Duplication) merupakan peniruan suatu produk, jasa, atau proses yang telah ada. Meskipun demikian, duplikasi bukan semata meniru melainkan menambah sentuhan kreatif untuk memperbaiki konsep agar lebih mampu memenangkan persaingan.

d. Sintesis (Synthesis) merupakan perpaduan konsep dan faktor-faktor yang sudah ada menjadi formulasi baru. Proses ini meliputi pengambilan sejumlah ide atau produk yang sudah ditemukan dan dibentuk sehingga menjadi produk yang dapat diaplikasikan dengan cara baru.

Berdasarkan berbagai pengertian inovasi serta macam-macam inovasi di atas, maka inovasi dapat dimaknai secara luas ataupun sempit. Inovasi yang bermakna luas yaitu pengenalan produk baru dan lebih baik serta penerapan metode bisnis dan proses produksi baru, sedangkan inovasi yang bermakna sempit bermakna teknologi baru baik berupa produk dan/atau proses serta pengembangan dan/atau penyempurnaannya. 


\subsection{Esensi Disruptive Innovation}

Istilah disruptive innovation dikembangkan oleh Christensen dalam publikasinya pada akhir tahun 90-an. Sejalan dengan itu, Chang Che Hang dkk (2013: 6) menyatakan:"Disruptive innovation (DI) is a process by which a product or service takes root initially in simple applications at the bottom of a market or in a new market, and then relentlessly moves 'up market', eventually displacing established competitors" (Disruptive innovation adalah proses di mana suatu produk atau jasa yang awalnya berakar pada aplikasi sederhana di bagian bawah pasar atau di pasar baru,dan kemudian bergerak tanpa henti ke atas pasar, yang akhirnya menggeser pesaing yang sudah mapan).

Menurut Utterback \& Acee, teori disruptive innovation mengambil perluasan dari formulasi orisinal ke formulasi strategi yang lebih umum dari strategi ekspansi pasar. (Chang Che Hang, 2013: 6) Sementara itu, Maitrayee Ghosh menyatakan: "Disruptive innovation is the technology that changes the existing business model, or customer expectitions" (Disruptive innovation adalah teknologi yang mengubah model bisnis konvensional atau harapan konsumen).

Disruptive Innovation, dalam bahasa Indonesia yang disadur bebas berarti inovasi yang mengacau atau inovasi yang mengganggu. Kata mengganggu pada konteks ini tidak dapat diambil maknanya secara bebas begitu saja. Sejalan dengan perkembangan teknologi, mengganggu dalam konteks ini bermakna bahwa munculnya inovasi teknologi baru akan mengganggu keberadaan teknologi yang lama.

Pengertian persaingan pasar pada keilmuan ekonomi yang lampau sering menjadikan harga sebagai parameter utama dalam melihat faktor yang mempengaruhi persaingan itu sendiri (Wahyuningtias G dkk, 2014: 2). Namun sering dilupakan bahwa dalam persaingan pasar yang modern, teknologi mempunyai pengaruh yang sangat besar. Terlebih untuk perusahaan yang sudah mapan dan merasa memimpin industri, seringkali ego dan kepercayaan diri yang terlampau besar menutup mata terhadap inovasi yang dilakukan pesaing atau pendatang baru. Teknologi yang muncul setelahnya perlahan dapat diterima konsumen dan menggantikan teknologi yang disediakan oleh perusahaan yang sudah mapan tersebut. Bagaimanapun juga, inilah dasar 
bagaimana inovasi yang menggantikan dan lebih mudah itu disebut sebagai inovasi yang menggangu.

Hadirnya fenomena disruptive innovation telah membawa dunia berubah lebih cepat dari sebelumnya. Globalisasi, jaringan sosial, mobilitas professional, dan keresahan para pekerja telah merata serta memaksa perusahaan untuk fokus dengan pengetahuan pekerjanya. Saat ini, diakui ada banyak pelaku bisnis terganggu oleh globalisasi, pergeseran teknologi, dan pesaing baru. Mereka dipaksa harus menemukan kembali identitas perusahaan mereka. Bahkan di perusahaan-perusahaan yang sehat, inovasi model bisnis sangat penting untuk mempertahankan posisi kompetitif mereka. Model bisnis bergeser dari tempat kerja ke jalanan.

Hadirnya fenomena disruptive innovation ini telah melahirkan berbagai macam inovasi dalam bidang teknologi. Inovasi dalam bidang teknologi tidak pernah terjadi tanpa mengubah struktur industri secara konvensional. (Jon M. Garon, 2012 : 441) Inovasi dalam bidang teknologi ini telah merubah model bisnis konvensional yang bermuara pada perubahan paradigma yang mendasar. Paradigma inovasi dalam bidang teknologi telah mengalami pergeseran dari sustaining technology ke disruptive technology. Dalam pandangan Christensenada perbedaan antara sustaining dan disruptive technology, la menyatakan:"Sustaining technologies improve performance, increase margins, and build customer relations, disrupting technologies often start out as unusable innovations that underperform, cost too much, or focus on a different customer base." (Jon M. Garon, 2012: 442) (Teknologi yang berkelanjutan meningkatkan kinerja, meningkatkan margin, dan membangun hubungan dengan pelanggan, teknologi yang mengganggu sering kali dimulai sebagai inovasi yang tidak dapat digunakan dengan tidak mencapai standar pasar, tidak terlalu mahal, atau fokus pada basis pelanggan yang berbeda).

Disruptive innovation atau inovasi yang mengganggu mulai dipopulerkan oleh Christensen pada tahun 1997 sehingga perlu dimengerti beberapa hal. Pertama, tidak perlu diperdebatkan kapan pertama kali inovasi yang mengganggu tersebut muncul di dunia karena istilah inovasi yang mengganggu baru diperkenalkan Christensen pada tahun 1997. Berbagai inovasi yang dapat dikatakan inovasi yang mengganggu dibatasi dalam lingkup setelah istilah itu diperkenalkan. Kedua, inovasi dapat dikatakan sebagai inovasi mengganggu 
jika inovasi tersebut membawa teknologi baru yang lebih murah dan memudahkan dibandingkan dengan teknologi yang telah ada. Efisiensi yang ditawarkan karena harga yang murah pada akhirnya mengganggu teknologi yang lama yang mahal dan tidak efisien. Ketiga, inovasi yang mengganggu terjadi pada industri yang sama, jika inovasi dilakukan tidak membuat pelaku industri lama terganggu, atau di lain pihak secara langsung mengganggu industri lain, maka inovasi tersebut tidak dikatakan sebagai inovasi yang mengganggu.

Inovasi yang mengganggu terjadi di belahan dunia. Di Eropa misalnya, kasus terbesar yang pernah terjadi misalnya perusahaan Nokia. Ponsel yang di masa jayanya dijuluki sebagai ponsel sejuta umat itu pada akhirnya harus mengakui handphone bersistem android dan Os sebagai inovasi yang mengganggu. Pada awalnya Nokia masih penuh percaya diri dengan sistem Symbiannya. Perusahaan itu merasa bahwa pasar yang dimiliki sangat tergantung pada sistem Symbiannya. Bahkan saat Apple merilis iPhone pada tahun 2007, Nokia tetap merasa tidak tersaingi dan meneruskan Symbiannya sebagai andalan. Sedangkan pesaing barunya, android, terus memantapkan posisinya dalam pasar. Pangsa pasar Symbian Nokia mulai turun ketika Apple mulai memperkenalkan iPhone 3G pada 2008.

Global market share held by Nokia in the mobile device market from 2010 to 2013

$\sin$

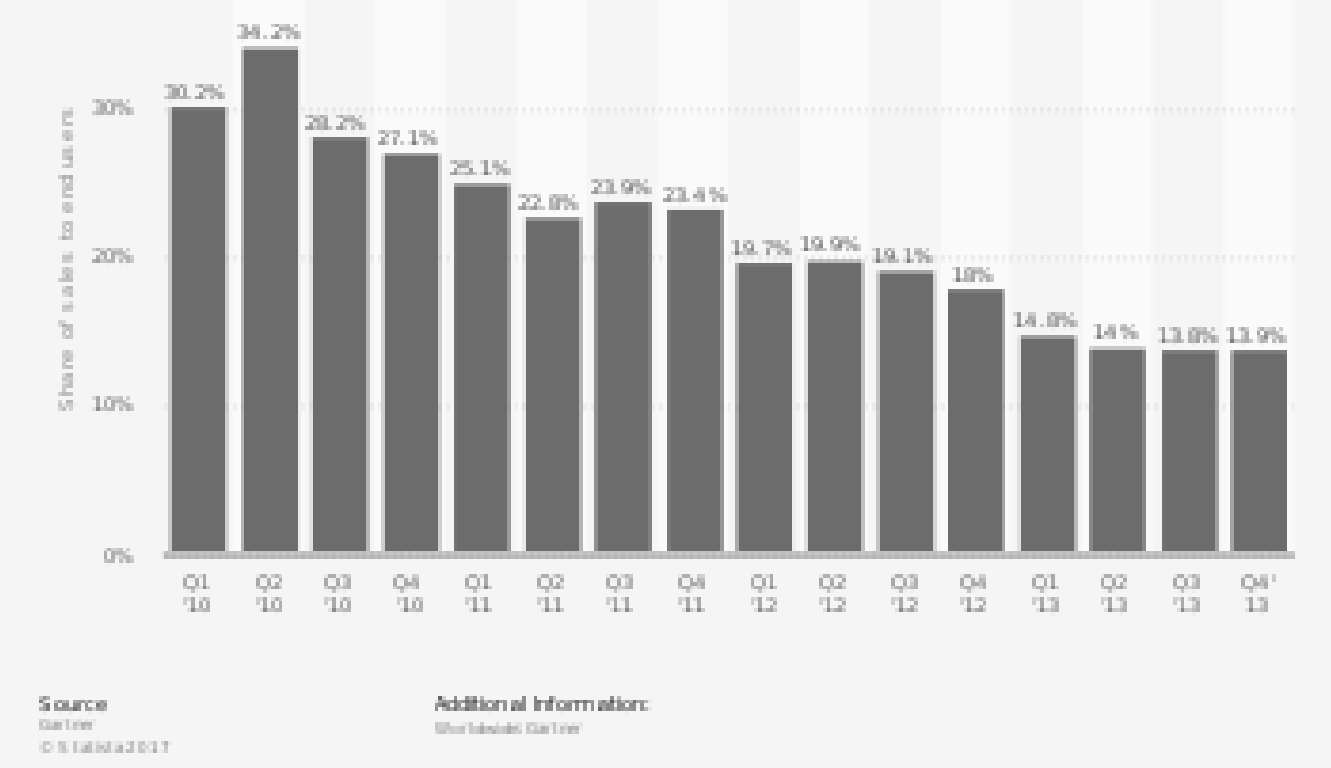

Sumber: https://www.statista.com/statistics/216513/global-market-share-of-nokia/ 


\subsection{Disruptive Innovation dalam Kajian Hukum Persaingan Usaha}

Taksi online adalah salah satu inovasi yang tergolong sebagai disruptive innovation. Persaingan antara taksi online dengan taksi konvensional tidak terelakkan lagi, walaupun dari segi bisnis pola kerjanya berbeda. Berbeda, karena perusahaan penyedia aplikasi tidak menyediakan mobil. Pada umumnya mobil adalah milik pengemudi sendiri dan hubungan antara pengemudi dengan perusahaan aplikasi adalah hubungan kerjasama yang dilakukan melalui koperasi dimana pengemudi bergabung. Definisi pasar bersangkutan dari perspektif hukum persaingan usaha juga menjadi isu.

Hal ini menjadi tantangan bagi Komisi Pengawas Persaingan Usaha (selanjutnya disebut KPPU) untuk melakukan penilaian atas persaingan di antara keduanya, karena seperti disebutkan oleh Christensen bahwa usaha disruptive innovation lebih murah, lebih gampang diperoleh dan menggunakan suatu model usaha dengan keunggulan biaya struktural (structural cost advantages).

Pertanyaannya adalah bagaimana lembaga persaingan usaha menilai dampak disruptive innovation terhadap persaingan usaha dan bagaimana penerapan hukum persaingan usaha terhadap pelaku usaha yang menggunakan disruptive innovation, yang dalam kenyataannya dapat mengalihkan minat pembeli dari pelaku usaha incumbent kepada pelaku usaha dengan disruptive innovation ? Oleh karena itu, sebelumnya, perlu dijawab apa sebenarnya tujuan hukum persaingan usaha? Secara umum disepakati bahwa tujuan persaingan usaha adalah untuk melindungi persaingan usaha itu sendiri bukan melindungi para pelaku usaha dan untuk mensejahterahkan konsumen. Sedangkan tujuan Undang-Undang Nomor 5 Tahun 1999 tentang Larangan Praktek Monopoli dan Persaingan Usaha Tidak Sehat adalah untuk meningkatkan kesejahteraan masyarakat (konsumen), mewujudkan iklim usaha yang kondusif melalui pengaturan persaingan usaha yang sehat, mencegah praktek monopoli dan atau persaingan usaha tidak sehat, dan terciptanya efektivitas dan efisiensi dalam kegiatan usaha.

Dalam menegakkan Undang-Undang Nomor 5 Tahun 1999 tentang Larangan Praktek Monopoli dan Persaingan Usaha Tidak Sehat, dasar pertimbangannya adalah untuk mencapai tujuan undang-undang tersebut. Oleh karena disruptive innovation dalam konteks online taksi, pola bisnisnya belum 
diatur dalam Undang-undang Lalulintas, maka diatur dalam Peraturan Menteri Perhubungan Nomor 32 Tahun 2016 tentang Penyelenggaraan Angkutan Orang Tidak Dalam Trayek yang diperbaharui menjadi Peraturan Menteri Perhubungan Nomor 26 Tahun 2017 (selanjutnya disingkat Permenhub No. 26/2017) untuk mengakui legalitas taksi online di Indonesia. Jadi ketika muncul masalah terutama menyangkut hubungan antara inovasi dan kebijakan persaingan, maka pemahaman bersama adalah bahwa KPPU harus melindungi proses inovasi dengan membiarkan pasar terbuka bagi para inovator potensial. Oleh karena itu, menentukan pasar yang bersangkutan atau mengklarifikasi struktur pasar sangat penting untuk menentukan apakah tindakan yang diambil oleh pelaku usaha di pasar bersangkutan bersifat antikompetitif atau tidak.

Definisi pasar sangat relevan dalam konteks disruptive innovation, karena salah satu karakteristik khas gangguan tersebut adalah kemampuannya untuk "mengganggu" pasar yang ada dan menghancurkan perusahaan incumbent. Apakah taksi online dengan taksi konvensional berada pada pasar bersangkutan yang sama? Dari sisi pasar secara sederhana dapat dijawab ya, tetapi dari sisi pasar sebaliknya (penawaran) perlu dikaji lebih dalam lagi, karena inovasi yang dilahirkan oleh taksi online adalah justru pada sistem aplikasi yang diciptakan yang mempermudah calon penumpang untuk mengordernya. Kemudian hubungan antara pengemudi taksi online dengan penyedia aplikasi harus dipertegas apakah hubungan kerja atau kerjasama, karena menurut Permenhub No. 26/2017 penyedia aplikasi yang mengadakan kerjasama dengan perusahaan transportasi publik, yaitu berupa koperasi. Dengan demikian untuk menganalisis market powernya dan posisi dominannya harus dijelaskan hal-hal tersebut guna menghitung biaya produksinya sehingga dapat menilai apakah harga yang ditawarkan oleh taksi online masih wajar atau tidak.

Berdasarkan pembahasan di atas, disruptive innovation mempunyai dampak besar terhadap persaingan pada pasar yang bersangkutan, yaitu terhadap konsumen, konsumen dapat disejahterahkan, dan terhadap persaingan, maka pelaku usaha konvensional harus berbenah untuk dapat bersaing. Langkah awal yang harus dilakukan oleh KPPU dalam menganalisis apakah perilaku taksi online melakukan anti persaingan atau tidak pada pasar yang bersangkutan, KPPU secara khusus menetapkan definisi pasar 
bersangkutan terlebih dahulu. Bahkan ketika pasar diubah atau diciptakan oleh inovator yang mengganggu, otoritas persaingan (KPPU) dihadapkan pada kebutuhan untuk segmentasi pasar yang ada atau menentukan pasar yang baru. Penentuan pasar bersangkutan sangat penting untuk menganalisis apakah taksi online melakukan anti persaingan dan apakah mempunyai market power dan posisi dominan yang dapat disalahgunakannya.

\section{KESIMPULAN}

"Disruptive Innovation" adalah fenomena global dalam kurun waktu satu dasawarsa terakhir berkat penggunaan teknologi informasi dan komunikasi. Inovasi ini telah mengubah banyak perspektif dalam berbisnis, yang intinya memberi pilihan yang lebih menguntungkan konsumen. Oleh sebab itu, inovasi seperti ini tidak mungkin dan memang tidak selayaknya dihambat, mengingat pasar yang inovatif (innovative market) merupakan salah satu syarat bagi pertumbuhan ekonomi.

Jikalau ada pandangan bahwa inovasi ini membawa dampak "disruptive" terhadap pelaku usaha yang sudah mapan, maka dampak inilah yang harus dikelola dengan baik oleh negara. Ketidakmampuan dalam pengelolaan hanya akan merusak struktur pasar, membuahkan instabilitas ekonomi, dan sosial. Pola pengelolaan pun tidak boleh sekadar diserahkan kepada mekanisme pasar bebas, melainkan harus mencermati dasar-dasar filosofis dan konstitusional negara, dengan kesejahteraan masyarakat dan keadilan sosial sebagai tujuan akhirnya.

\section{DAFTAR PUSTAKA}

\section{Buku}

Hamid, Edi Suandi, 2017, Disruptive Innovation: Manfaat dan Kekurangan Dalam Konteks Pembangunan Ekonomi. Makalah disampaikan dalam materi Seminar Nasional tentang Disruptive Innovation di Grand Inna Malioboro Yogyakarta, Rabu 27 Juli 2017.

Fizzanty, Trina dkk, 2014, "Konsep Ilmu Pengetahuan, Teknologi dan Inovasi”, Modul Diklat Jabatan Fungsional Peneliti Tk, LIPI, Jakarta. 
Garon, Jon M. 2012, "Mortgaging the Meme : Financing and Manging Disruptive Innovation" Northwestern Journal of Technology and Intellectual Property, Volume 10, Issue 7.

Hang, Chang Chedkk, 2013, Opportunity Discovery and Creation in Disruptive Innovation, Institutefor Manufacturing University of Cambridge, Cambridge.

Partanto, Pius A dan M.Dahlan Al Barry, 2001,Kamus Ilmiah Populer, Arkola,Surabaya.

Sanjaya, Wina, 2008, Kurikulum danPembelajaran(TeoritikdanPraktikKurikulum KTSP),Prenada MediaGroup, Jakarta.

Shapiro, Carl, 2005, Anti Trust, Innovation and Intellectual Property, Testimony Before the AntiTrust Modernization Commission, Anti Trust Commision.

Suharso dan Ana Retnoningsih, 2009, Kamus Besar Bahasa Indonesia, Edisi Lux, Widya Karya,Semarang.

Schumpeter,J.A, 2015, "theTheory of Economic Development: AnInquiry into Profits, Capital, Credit, Interestand The Business Cycle, "Harvard Economic Studies, Vol.46, Harvard College, Cambridge, MA, 1934 sebagaimana dikutip oleh Karol Śledzik, Schumpeter's View on Innovation and Entrepreneurship, University of Zilina, Polandia.

Wahyuningtias G, Inge \& Valcke, 2014, How Google and Others upset competition analysis: disruptive innovation and European competition law, International Telecommunications Society, Brussels.

\section{Internet}

Ghosh, Maitrayee, "Disruptive Innovation and Academy Library Management,"https://www.researchgate.net/publication/313051230, diakses pada tanggal 30 Juli 2017

Kalanje, Christoper M. Consultant, SMEs Division, WIPO. http:/www.wipo.int/sme/en/documents/ip_innovation_development.htm\#inn, diakses pada tanggal 30 Juli 2017.

Sumardiyani, Windiyati Retno dalam http://www.pikiran-rakyat.com/jawabarat/2017/07/20/. Diakses 30 Juli 2017.

Wahid, Ahmad Bil, 2017, dalam Detiknews, Diakses 30 Juli 2017.

http://thesis.binus.ac.id/doc/Bab2/2012-2-02013-MN\%20Bab2001.pdf diakses pada tanggal 30 Juli 2017.

https://en.oxfordictionaries.com/definition/innovation diakses pada tanggal 30 Juli 2017. 